\title{
Development and characterization of pumpkin crackers containing live culture of Lactobacillus acidophilus
}

\author{
Hui-Xian Lim¹, Chai-Ying Ong ${ }^{1}$, Chee Sian Kuan² and Siok-Koon Yeo ${ }^{1 *}$
}

${ }^{1}$ School of Biosciences, Taylor's University Lakeside Campus, 47500 Subang Jaya, Selangor Darul Ehsan, Malaysia. ${ }^{2}$ Neogenix Laboratoire Sdn Bhd, C707, Level 7, Block C, Kelana Square, Kelana Jaya, 47301 Petaling Jaya, Selangor, Malaysia.

Email: siokkoon.yeo@taylors.edu.my

Received 14 September 2018; Received in revised form 15 February 2019; Accepted 21 March 2019

\begin{abstract}
Aims: Up to date, there is limited heat-treated non-dairy probiotic food products in the market. Therefore, this study aims to develop a new functional cracker containing microencapsulated pumpkin-probiotics with acceptable sensory characteristics.

Methodology and results: The sample crackers (crackers with beads containing pumpkin and probiotic) have achieved a minimum required viable count of $6.26 \pm 0.05 \mathrm{Log}_{10} \mathrm{CFU} / \mathrm{g}$ and showed significantly $(p<0.05)$ lower viability loss compared to control crackers (crackers with beads containing probiotic only). Sample crackers were perceived as acceptable (score 6.61) by 93 untrained panelists when tested using 9-point hedonic test. The ash content of sample pumpkin crackers was significantly higher $(p<0.05)$ than the control. Both sample and control pumpkin crackers exhibit high level of total dietary fiber $(>6 \%)$.

Conclusion, significance and impact of study: In summary, development of pumpkin crackers with microencapsulated $L$. acidophilus could be an alternative healthy option cracker for consumers. In addition, the results also suggested a new technique to deliver live culture in baked goods.
\end{abstract}

Keywords: Microencapsulation, pumpkin, Lactobacillus, crackers, probiotics

\section{INTRODUCTION}

With the rapid urbanization and modernization lifestyle, eating habits of majority population have changed to convenient and time saving food products. Biscuits or crackers that fall under ready-to-eat or convenience food categories are commonly consumed among Malaysians. They are also the most popular ready-to-eat snack food in the world that act as a substitution for proper meal due to its conveniences and ability to cater for current busy lifestyle (Norhayati et al., 2015). Although biscuits are one of the most commonly consumed convenience foods, there are certain drawbacks including their hydrogenated fat composition which may lead to health concerns (Boobier et al., 2006). Consequently, healthier options such as low-fat, cereal-based, and vegetable-based biscuits with nutritional improvement were developed and produced by the industry.

Probiotics are defined as 'live microorganisms that provide health benefits to the host when consumed in adequate amount' (FAO/WHO, 2002). Due to the demand for overall health improvement, products containing probiotics are becoming more widely available and comprise between 60 to $70 \%$ of the entire functional food market (Tripathy and Giri, 2014). Lactobacilli is the most common bacterial genera to be incorporated into food, mainly dairy products such as yogurt and fermented milk (Iravani et al., 2015). However, consumption of excessive dairy products has been correlated to some health issues such as lactose intolerance and hypercholesterolemic. Therefore, there is an increased demand for non-dairy probiotic products such as soy-based drinks, fruit, and vegetable-based products as well as other cereal-based products (Granato et al., 2010).

As recommended by the United State Food and Drug Administration, the minimum probiotic count in probiotic food products should be at least $10^{6} \mathrm{CFU} / \mathrm{mL}$ to exert health benefits. The survivability of probiotics in food is highly influenced by factors like $\mathrm{pH}$, storage temperature, oxygen levels, and manufacturing process. To overcome these, microencapsulation technique is introduced to protect the cells from hostile conditions such as high acidity conditions, thermal processing condition, and others (Malmo et al., 2013). Past studies have shown that 
microencapsulation can improve heat tolerance and increase the probiotics survival rate during heat processing (Seyedain-Ardabili et al., 2016). The authors showed that the viability of probiotic in high heat treatment products such as bread was enhanced by encapsulation technique during baking process (at $180^{\circ} \mathrm{C}$ for 15 min). In contrast, Malmo et al. (2013) demonstrated that chitosan-alginate microencapsulation system achieved only $10 \%$ survival rate of probiotic population in chocolate soufflé (baking at $180{ }^{\circ} \mathrm{C}$ for $10 \mathrm{~min}$ ). This contradicting finding showed that there is still lack of study on utilizing encapsulation techniques effectively in developing high heat treatment probiotic goods leading to limited probiotics containing baked goods in the current market.

Fruits and vegetables are good source of fibers, vitamins, and minerals. They are mainly incorporated into a balanced diet due to the presence of antioxidants that provide protective effect against various diseases (Dhandevi and Rajesh, 2015). Pumpkin is a fruit vegetable that has an excellent source of carotenoids and contain significant amount of proteins and fibres (Norshazila et al., 2017). Given the good nutritional value, pumpkins can be used in the form of flour for production of ready-to-eat food such as snack and breakfast cereal products. Furthermore, the fiber content, especially the soluble fiber such as pectin found in pumpkin has prebiotic effects to support the growth of probiotics (de Souza et al., 2017). Therefore, it is postulated that using pumpkin extract in microencapsulation of probiotic may improve the viability of probiotic. Thus, the aim of this study is to develop a functional cracker that contain probiotics and to evaluate the effect of pumpkin puree supplementation in probiotic microencapsulation on the physicochemical and sensory characteristics of the crackers.

\section{MATERIALS AND METHODS}

\section{Bacteria culture preparation}

Lactobacillus acidophilus ATCC 314 culture was activated for three successive times in sterilized de Mann Rogosa Sharpe (MRS) broth (Merck KGaA, Darmstadt, Germany) at $37{ }^{\circ} \mathrm{C}$ for $24 \mathrm{~h}$. The consistency of the cultures concentration was standardized at optical density $\left(\mathrm{OD}_{600}\right)$ $=1.20$. The activated cultures were then washed three times using $0.9 \%(\mathrm{w} / \mathrm{v})$ sterilized saline water by centrifugation at $4000 \mathrm{rpm}$ at $4{ }^{\circ} \mathrm{C}$ for $10 \mathrm{~min}$. The cell pellet was then harvested for further analyses.

\section{Preparation of pumpkin puree}

Fresh pumpkin was purchased from local supermarket (Selangor, Malaysia). Pumpkin was peeled and sliced prior to heating in microwave for 3 min and subsequently mashed. The mashed pumpkin was blended for $1 \mathrm{~min}$ in order to smoothen the puree. The resultant blended pumpkin puree was stored at $4{ }^{\circ} \mathrm{C}$ prior to formulation of cracker and microencapsulation.

\section{Microencapsulation}

Microencapsulation of culture was done using extrusion method (Rathore et al., 2013). The microencapsulated beads were prepared by mixing the bacteria cultures of $\mathrm{OD}_{600}=1.20$ with $2 \%(\mathrm{w} / \mathrm{v})$ sodium alginate (Modernist Pantry, Eliot, ME, USA) solution in 1:1 ratio (v:v). Pumpkin puree $(10 \mathrm{~g})$ was then added into the mixture. Pumpkin puree was replaced with distilled water to prepare control beads. The mixtures were then added into $50 \mathrm{~mL}$ syringe (Becton Dickinson and Company, Temse, Belgium) with needle of $23 \mathrm{G} \times 1 \frac{11 / 4}{4}$ size (Terumo Neolus, London, UK) that was fixed to the encapsulator (Chemopharm Sdn Bhd, Selangor, Malaysia). The mixture was extruded at a constant rate of $15 \mathrm{~mL} / \mathrm{min}$ from the syringe directly to $0.3 \mathrm{M}$ calcium chloride solution (Modernist Pantry, Eliot, ME, USA) to form gel-like beads. The beads were collected and froze at $-20^{\circ} \mathrm{C}$ overnight prior to freeze-drying process.

\section{Production of pumpkin cracker with freeze dried beads}

All the ingredients for crackers were purchased from local supermarket in Selangor, Malaysia. All ingredients including all-purpose flour $(51 \%, \mathrm{w} / \mathrm{w})$, pumpkin puree $(23 \%, w / w)$, olive oil $(14 \%, w / w)$, cornstarch $(7 \%, w / w)$, fine granulated sugar $(4 \%, w / w)$, baking powder $(0.7 \%$, $\mathrm{w} / \mathrm{w})$, and fine salt $(0.3 \%, \mathrm{w} / \mathrm{w})$ were mixed and kneaded to form cracker dough. Both $0.05 \%(\mathrm{w} / \mathrm{w})$ of control and pumpkin freeze dried beads were added into respective cracker dough. The crackers were molded into square shape with length of $2.7 \mathrm{~cm}$ and $0.15 \mathrm{~cm}$ height. The crackers were baked (C\&N United, Selangor, Malaysia) at $150{ }^{\circ} \mathrm{C}$ for $20 \mathrm{~min}$.

\section{Sensory evaluation}

Ninety-three untrained panelists ( $18-45$ years old) were recruited for the sensory evaluation. Sensory properties such as appearance, aroma, texture, taste, and overall acceptance were evaluated using 9-points hedonic scale. Panelists were served with three type of crackers, blank (without probiotics beads), control (with probiotics beads), and sample (with pumpkin-probiotics beads). Each type of cracker was served with three-digit coding at random order. Panelists were required to rinse their palate in between samples with plain water.

\section{Viability of probiotics in freeze dried beads and crackers}

The viability of probiotics was determined according to the method of D'Orazio et al. (2015), with slight modification. Finely ground control and sample crackers $(10 \mathrm{~g})$ were mix vigorously with $20 \mathrm{~mL}$ phosphate buffer saline solution of $\mathrm{pH}$ 7.4, $0.1 \mathrm{M}$ (Sigma-Aldrich ${ }^{\circledR}$, St. Loius, MO, USA) for $30 \pm 5 \mathrm{~min}$ to release the cells from the encapsulated materials. Pour plate method with MRS agar (Merck KGaA, Darmstadt, Germany) was used to 
enumerate the viability of probiotics. Triplicate plate was incubated at $37^{\circ} \mathrm{C}$ for $48 \mathrm{~h}$.

\section{Proximate Analysis}

\section{Moisture analysis}

The moisture content of cracker was determined using oven drying method (AOAC 925.10) (AOAC, 2000). Finely grinded cracker $(5 \mathrm{~g})$ was dried at $120{ }^{\circ} \mathrm{C}$ until constant weight was achieved. The moisture content of cracker was determined based on the weight loss after drying.

\section{Protein analysis}

Nitrogen content of cracker was determined based on Kjeldahl method (AOAC 950.36), using Kjeldatherm digestion unit (Gerhardt, Konigswinter, Germany) and Vapodest Kjeldahl Distillation System (Gerhardt, Konigswinter, Germany) (AOAC, 2000). The nitrogen content was converted to protein content by multiplying with a nitrogen-protein conversion factor of 6.25 (Jeon, 1994).

\section{Fat analysis}

Fat content of cracker was determined based on Soxhlet Extraction Method (AOAC 920.39), using SOXTHERM rapid extraction system (Gerhardt, Konigswinter, Germany) (AOAC, 2000).

\section{Ash analysis}

The ash content of crackers was analysed based on dry ashing method (AOAC Method 923.03) (AOAC, 2000). Approximately $10 \mathrm{~g}$ of dried homogenized cracker was placed in porcelain crucible and inserted into muffle furnace (Nabertherm, Lilienthal, Germany) at $600{ }^{\circ} \mathrm{C}$ for overnight.

\section{Carbohydrate determination}

The carbohydrate content of cracker was determined by difference method (Jeon, 1994).

\section{Total dietary fiber determination}

Moisture and fat free samples were analysed for their total dietary fiber by enzymatic and gravimetric method according to AOAC 985.29 method (AOAC, 2000) using TDF-100 kit (Sigma, St. Loius, MO, USA). Samples (1.0 \pm $0.1 \mathrm{~g})$ were digested with $\alpha$-amylase, protease, and amyloglucosidase according to manufacturer suggestion (Sigma, St. Loius, MO, USA). Heated $\left(60{ }^{\circ} \mathrm{C}\right) \quad 95 \%$ ethanol was added and the solution was left to precipitate at room temperature for $1 \mathrm{~h}$. Digested samples were filtered using Fibertec 1023 system (FOSS, Hillerod, Denmark). Crucibles containing residues from filtration was dried and weighed. Sample containing dietary fiber residues were then later used for protein and ash content determination to calculate total dietary fiber values, protein and ash content.

\section{Texture analysis}

Hardness of crackers was determined by using Brookfield CT3 texture analyser (Middleboro, MA, USA) according to Yilmaz et al. (2014), with slight modification. The texture analyser was attached with Knife edge probe (TA7, 60 $\mathrm{mm} \mathrm{W}$ ) and set at pretest speed $1 \mathrm{~mm} / \mathrm{s}$, test speed 5 $\mathrm{mm} / \mathrm{s}$, and $1000 \mathrm{~g}$ trigger load.

\section{Statistical analysis}

The results obtained were analyzed statistically using Microsoft Excel and IBM SPSS Statistics 20 (SPSS Inc., Armonk, NY, USA). All data obtained were analyzed at a $5 \%$ level of significance $(\alpha=0.05)$. Independent t-test was performed for all analysis except sensory evaluation. One-way analysis of variance ANOVA was applied for the sensory evaluation and statistical difference was analyzed with post-hoc Tukey HSD. All data was presented as mean \pm standard deviation from duplicate of three independent runs unless stated otherwise.

\section{RESULTS AND DISCUSSION}

\section{Sensory evaluation}

In the food industry, sensory evaluation is used as a primary parameter to determine the success of a new product development, while other forms of quality parameters such as wholesomeness as well as nutrition are mainly considered secondary (Singh-Ackbarali and Maharaj, 2014). Hence, it is important to ensure the food quality is appealing and highly acceptable by the consumer in terms of appearance, aroma, taste, texture and others. In this study, sensory evaluation was carried out with 9-point hedonic scale to analyze the consumers' acceptance on sample (beads containing pumpkin and probiotic) in comparison to blank (without beads) and control (beads containing probiotic) pumpkin crackers. Based on the results obtained, presence of encapsulated beads in sample crackers did not affect the perception of participants on the crackers' appearance compared to the blank. Since pumpkin puree imparts the desirable colour in all three types of crackers, all crackers exhibited similar colour (Table 1) as similar amount of pumpkin puree was used for the crackers.

There was also no significant difference $(p>0.05)$ between all the crackers in terms of aroma, gritiness, crunchiness, taste and overall acceptance. This showed that the microencapsulation techniques produced beads that are sufficiently small and not perceivable by the consumers compared to blank (without the micro-beads). Based on Table 1, all the mean scores obtained were between 6 (like slightly) to 7 (like moderately) which indicated that all the pumpkin crackers were generally accepted by the panelists. Considering that all the crackers showed similar acceptance by consumer, both 
Malays. J. Microbiol. Vol 15(5) 2019, pp. 366-372

DOI: http://dx.doi.org/10.21161/mjm.180238

Table 1: Hedonic scores of sensory attributes for control, sample and blank pumpkin crackers.

\begin{tabular}{lccc}
\hline \multirow{2}{*}{ Attribute } & \multicolumn{3}{c}{ Type of Pumpkin Crackers } \\
\cline { 2 - 4 } & Control & Sample & Blank \\
\hline Colour & $6.49 \pm 1.14^{\mathrm{a}}$ & $6.55 \pm 1.23^{\mathrm{a}}$ & $6.87 \pm 1.27^{\mathrm{a}}$ \\
Thickness & $6.18 \pm 1.29^{\mathrm{a}}$ & $6.29 \pm 1.34^{\mathrm{ab}}$ & $6.70 \pm 1.57^{\mathrm{b}}$ \\
Overall appearance & $6.52 \pm 1.15^{\mathrm{a}}$ & $6.58 \pm 1.16^{\mathrm{ab}}$ & $6.95 \pm 1.19^{\mathrm{b}}$ \\
Overall aroma & $6.61 \pm 1.42^{\mathrm{a}}$ & $6.73 \pm 1.30^{\mathrm{a}}$ & $6.26 \pm 1.48^{\mathrm{a}}$ \\
Crunchiness & $5.95 \pm 1.53^{\mathrm{a}}$ & $6.20 \pm 1.56^{\mathrm{a}}$ & $6.35 \pm 1.59^{\mathrm{a}}$ \\
Grittiness & $5.73 \pm 1.75^{\mathrm{a}}$ & $5.80 \pm 1.53^{\mathrm{a}}$ & $6.05 \pm 1.58^{\mathrm{a}}$ \\
Overall texture & $6.24 \pm 1.52^{\mathrm{a}}$ & $6.25 \pm 1.33^{\mathrm{a}}$ & $6.66 \pm 1.38^{\mathrm{a}}$ \\
Sweetness & $6.11 \pm 1.62^{\mathrm{a}}$ & $6.02 \pm 1.53^{\mathrm{a}}$ & $6.08 \pm 1.65^{\mathrm{a}}$ \\
After taste & $6.17 \pm 1.38^{\mathrm{a}}$ & $6.42 \pm 1.46^{\mathrm{a}}$ & $6.43 \pm 1.57^{\mathrm{a}}$ \\
Overall taste & $6.49 \pm 1.30^{\mathrm{a}}$ & $6.54 \pm 1.32^{\mathrm{a}}$ & $6.64 \pm 1.40^{\mathrm{a}}$ \\
Overall acceptance & $6.37 \pm 1.40^{\mathrm{a}}$ & $6.61 \pm 1.10^{\mathrm{a}}$ & $6.76 \pm 1.41^{\mathrm{a}}$ \\
\hline
\end{tabular}

${ }^{*}$ Results are expressed as means \pm standard deviations with $n=93$

${ }^{\mathrm{ab}}$ Means in the same column with different lowercase superscript letters are significantly different $(p<0.05)$.

\section{Viability Test}

Viability of L. acidophilus ATCC 314 was evaluated in this research to provide information about the effects of pumpkin puree supplementation on the survivability of probiotics after baking process. High baking temperature at $150{ }^{\circ} \mathrm{C}$ for 20 min may provide a harsh condition that may lead to a significant loss of viable cells. Therefore, microencapsulation technique was carried out to improve the survivability of probiotics. Microencapsulation can protect cells from harsh conditions such as high temperature where past researchers has proven that the survival of $L$. acidophilus encapsulated in starch was improved with a high viable count of $10^{6} \mathrm{CFU}$ per bread after baking at $180{ }^{\circ} \mathrm{C}$ for $16 \mathrm{~min}$ (Altamirano-Fortoul et al., 2012).

The final viability and total viability loss of $L$. acidophilus in both control and sample crackers were shown in Table 2 . The initial viability of probiotics was $8.14 \pm 0.08 \mathrm{Log}_{10} \mathrm{CFU} / \mathrm{g}\left(\mathrm{OD}_{600}=1.20\right)$. The final viability of sample pumpkin cracker $\left(10^{6} \mathrm{CFU} / \mathrm{g}\right)$ was significantly $(p<0.05)$ higher than the control pumpkin cracker. The viability loss of sample crackers was 1 Log lower compared to control crackers. This might be due to the extra nutrients provided by the pumpkin in the microcapsules as pumpkin is a good source of carbohydrate, pectin, mineral salts, and vitamins (Yok et al., 2015). Previous studies have demonstrated that the addition of protectants such as prebiotics, carbohydrate, and protein can minimize the viability loss of probiotics during heat processing and storage (Savedboworn et al., 2017). Therefore, it is likely that the carbohydrate and pectin in pumpkin may act as extra protectant towards probiotic cells. Pectins also exhibits prebiotic activities that can act as a growth stimulator for probiotics (de Souza et al., 2017).

According to Sarvari et al. (2014), a minimum dose of $10^{6} \mathrm{CFU} / \mathrm{g}$ in food product is required for different species and strains of probiotic to confer health benefits. Hence, probiotic food product should contain high initial cell counts during food production to ensure sufficient number of cells at the point of consumption (Farnworth, 2008). Our results showed that the sample crackers have achieved the minimum bacterial count for probiotic-based food products.

Genevois et al. (2016) reported that lactobacilli strains could metabolize and adhere to pumpkin's polysaccharides. Moreover, the oligosaccharides from pumpkin pulp has shown to stimulate growth of lactobacilli and showed a good resistance to hydrolysis in artificial human gastric juice (Du et al., 2011). Hence, this suggested that pumpkin could serve as a carrier to ensure there was sufficient viable probiotics to exert health benefits to host. This may explain our results of lesser viability loss in sample crackers containing pumpkin microencapsulated compared to the control.

Table 2: Viability of L. acidophilus ATCC 314 in control and sample pumpkin crackers.

\begin{tabular}{lcc} 
& $\begin{array}{c}\text { Control } \\
\left(\log _{10} \mathrm{CFU} / \mathrm{g}\right)\end{array}$ & $\begin{array}{c}\text { Sample } \\
\left.\left(\log _{10} \mathrm{CFU} / \mathrm{g}\right)\right)\end{array}$ \\
\hline Final Viability & $5.30 \pm 0.30^{\mathrm{a}}$ & $6.26 \pm 0.05^{\mathrm{b}}$ \\
Viability Loss & $2.84 \pm 0.30^{\mathrm{a}}$ & $1.88 \pm 0.05^{\mathrm{b}}$ \\
\hline
\end{tabular}

* The initial viable counts $\left(\mathrm{OD}_{600}=1.20\right)$ was $8.14 \pm 0.079 \log _{10}$ $(\mathrm{CFU} / \mathrm{g})$. Results are expressed as means \pm standard deviations $(\mathrm{n}=3)$.

ab Means in the same row with different lowercase superscript letters are significantly different $(p<0.05)$.

control and samples crackers were then used for viability test and other analyses.

\section{Proximate and total dietary fiber analysis}

Table 3 shows the comparison of percentage of proximate compositions of control and sample pumpkin 
crackers. Baked products specifically biscuits and crackers, are highly affected by the amount of moisture content present in the food. In order to have a longer shelf life, the moisture content of biscuit should be low (1-5\%), excluding any moisture from fillings or icings. Moreover, low moisture content in the food system is also required to ensure maximum survival of probiotics in a dry glassy matrix. This is because survival of probiotic in a solid matrix is affected when exposed to different temperature. An increased in moisture content, will decrease the glass transition temperature and affect the viability of probiotics (Zhang et al., 2018). Thus, moisture content of the pumpkin crackers was evaluated in this study. Based on Table 3, the moisture contents for control and sample crackers were $3.73 \%$ and $4.49 \%$, respectively. Sample cracker was found to have significantly $(p<0.05)$ higher moisture content compared to control cracker. This might be due to the moisture content contributed by the pumpkin puree in the beads. Fresh pumpkin is known to have $80.0-96.0 \mathrm{~g} / 100 \mathrm{~g}$ of moisture content (Guiné et al., 2011). The moisture content of shelf stable commercial biscuits ranges from 1.98 to $4.67 \mathrm{~g} / 100 \mathrm{~g}$ (Norhayati et al., 2015) which is in tandem with the results obtained in this study. Hence, this suggested that pumpkin crackers produced in this study are shelf stable.

There were no significant differences $(p>0.05)$ observed in fat, protein, and carbohydrate content of both pumpkin crackers (Table 3). The protein content in both pumpkin crackers were approximately $10 \%$. The protein content was mostly contributed by pumpkin which is a good source of amino acids with $12.9 \%$ of crude protein in dry basis as well as all-purpose flour with $9 \mathrm{~g} / 100 \mathrm{~g}$ of protein (Gurung et al., 2016). The fat contents of both control and sample crackers were $3.88 \%$ and $3.51 \%$, respectively which found to be lower compared to the commercial biscuits which ranged from 16.89 to 25.75 $\mathrm{g} / 100 \mathrm{~g}$ (Norhayati et al. 2015). The carbohydrate content of pumpkin crackers could be contributed by carbohydrate content in ingredients such as all-purpose flour (74.0 $\mathrm{g} / 100 \mathrm{~g})$, corn starch $(90.3 \mathrm{~g} / 100 \mathrm{~g})$, and pumpkin. As pumpkin puree contains a total of $68.3 \%$ of carbohydrate in dry basis (Gurung et al., 2016), it can be denoted that pumpkin puree can be a good source of energy. Moreover, the carbohydrate content in the pumpkin crackers are higher compared to commercial biscuits with a range of $56.80 \mathrm{~g}$ to $74.61 \mathrm{~g} / 100 \mathrm{~g}$ (Passos et al., 2013) and may serve as breakfast alternatives. Breakfast is one of the critical meals which help to replenish the body's fuel stores after an overnight fasting. A carbohydrate-rich diet or food product is preferred for breakfast as it able to boost the energy, enhanced alertness, and increase satiety level as well as controlling the appetite throughout the rest of the day (Holt et al., 1999). It is one of the preferred fuels for muscle and nerve functions as it is able to increase the blood glucose level when ingested.

The sample crackers showed significantly $(p<0.05)$ higher ash content than the control crackers. Fresh pumpkin is known to have around $0.8-1.4 \mathrm{~g} / 100 \mathrm{~g}$ or about $1.1 \mathrm{~g} / 100 \mathrm{~g}$ of ash (Guiné et al., 2011). According to Gurung et al. (2016), the ash content in pumpkins include potassium, copper, zinc, iron, and magnesium of pumpkin puree. Therefore, the increased in the ash content of sample crackers is most likely contributed by the additional pumpkin puree in the beads.

Total dietary fiber is the measurement of soluble and insoluble fiber in food. Based on Table 3, the total dietary fiber content for control and sample pumpkin crackers were comparable at $10.78 \%$ and $9.92 \%$, respectively. In a study conducted by Norhayati et al. (2015), 7.03\% was observed for total dietary fiber in a commercial oatmeal biscuit. The comparison between the pumpkin crackers and commercial biscuit showed that pumpkin crackers exhibits a higher amount of dietary fiber. This could be attributed to natural dietary fiber content of pumpkin puree.

Table 3: Percentage of proximate and total dietary fiber content of control and sample pumpkin crackers.

\begin{tabular}{lcc} 
& Control (\%) & Sample (\%) \\
\hline Moisture & $3.73 \pm 0.09^{\mathrm{a}}$ & $4.49 \pm 0.21^{\mathrm{b}}$ \\
Protein & $9.93 \pm 0.03^{\mathrm{a}}$ & $9.91 \pm 0.05^{\mathrm{a}}$ \\
Fat & $3.88 \pm 0.29^{\mathrm{a}}$ & $3.51 \pm 0.36^{\mathrm{a}}$ \\
Ash & $1.80 \pm 0.02^{\mathrm{a}}$ & $2.03 \pm 0.12^{\mathrm{b}}$ \\
Carbohydrate & $80.67 \pm 0.19^{\mathrm{a}}$ & $80.06 \pm 0.20^{\mathrm{a}}$ \\
Total Dietary & $10.78 \pm 0.56^{\mathrm{a}}$ & $9.92 \pm 0.56^{\mathrm{a}}$ \\
Fiber &
\end{tabular}

${ }^{*}$ Results are expressed as means \pm standard deviations $(n=3)$.

ab Means in the same row with different lowercase superscript letters are significantly different $(p<0.05)$.

\section{Physical Analysis}

\section{Texture profile analysis}

Texture is the critical physical attribute that dominate the quality and sensory acceptability of a product. Therefore, instrumental measurement such as texture profile analyzer was used to measure the food quality and for quality control in industries. Texture profile analysis is a rapid evaluation method for food texture with various parameters such as hardness, cohesiveness, gumminess, and others. Among these, hardness is the most frequently measured textural property for evaluation of baked goods due to its close association with human perception for freshness.

In this study, the hardness of both crackers was comparable ( $p>0.05 ;$ Table 4$)$. This indicates that incorporation of pumpkin beads will not affect the hardness of the crackers. According to study by Yilmaz et al. (2014), the hardness of a plain cracker is approximately $3561 \pm 297 \mathrm{~g}$. Besides that, Galla et al. (2017) found that a plain biscuit exhibit hardness of 2138 $\pm 4.04 \mathrm{~g}$. Thus, the pumpkin crackers that was produced in this study were less hard compared to the previous studies. This is desirable as excessive hardness will lead to brittleness that may affect the acceptability of the products. Furthermore, hardness of crackers is also affected by the application of dietary fiber from the pumpkin puree (Dokic et al., 2015). A study from Galla et 
al. (2017) found that increased in the supplementation of vegetable (spinach) in biscuit will increase hardness of the biscuits. Although dietary fibers from pumpkin puree might affect the hardness of the crackers, this was not prevalent in this study.

Table 4: Texture analysis of control and sample pumpkin crackers.

\begin{tabular}{cc}
\hline Crackers & Hardness $(\mathrm{g})$ \\
\hline Control & $1906.67 \pm 217.72^{\mathrm{a}}$ \\
Sample & $1732.00 \pm 410.77^{\mathrm{a}}$ \\
\hline
\end{tabular}

${ }^{*}$ Results are expressed as means \pm standard deviation $(n=3)$

a Means in the same column wibth different lowercase superscript

letters are significantly different $(p<0.05)$.

\section{CONCLUSION}

Cracker with live culture can be successfully develop by microencapsulating the cells with pumpkin puree. These crackers can serve as an alternative probiotic product with acceptable physicochemical properties.

\section{ACKNOWLEDGEMENTS}

This work was financially supported by Taylor's Research Grant Scheme (TRGS)- TRGS/MFS/2/2016/SBS/007.

\section{REFERENCES}

Altamirano-Fortoul, R., Moreno-Terrazas, R., Quezada-Gallo, A. and Rosell, C. M. (2012). Viability of some probiotic coatings in bread and its effect on the crust mechanical properties. Food Hydrocolloid 29, 166-174.

AOAC. (2000). Official Methods of Analysis, 17th edn. AOAC International, Gaithersburg, MD, USA.

Boobier, W. J., Baker, J. S. and Davies, B. (2006). Development of a healthy biscuit: An alternative approach to biscuit manufacture. Nutrition Journal 5, 1-7.

de Souza, J. R. R., Maciel, J. S., Brito, E. S., Ricardo, N. M. P. and Feitos,a J. P. A. (2017). Pectin from Cucurbita moschata Pumpkin Mesocarp. Macromolecules: An Indian Journal 12, 110-111.

Dhandevi, P. and Rajesh, J. (2015). Fruit and vegetable intake: Benefits and progress of nutrition education interventions-narrative review article. Iranian Journal of Public Health 44, 1309-1321.

Dokic, L., Nikolic, I., Soronja-Simovic, D., Seres, Z., Pajin, B., Juul, N. and Maravic, N. (2015). Rheological properties of dough and sensory quality of crackers with dietary fibers. International Journal of Nutrition and Food Processing 9, 985-989.

D’Orazio, G., Gennaro, P. D., Boccarusso, M., Presti, I., Bizzaro, G., Giardina, S., Michelotti, A., Labra, M. and La Ferla, B. (2015). Microencapsulation of new probiotic formulations for gastrointestinal delivery: In vitro study to assess viability and biological properties.
Applied Microbiology and Biotechnology 99, 97799789.

Du, B., Song, Y., Hu X., Liao, X., Ni, Y. and Li, Q. (2011). Oligosaccharides prepared by acid hydrolysis of polysaccharides from pumpkin (Cucurbita moschata) pulp and their prebiotic activities. International Journal of Food Science and Technology 4, 982-987.

Farnworth, E. R. (2008). The evidence to support health claims for probiotics. Journal of Nutrition 138, 1250s$1254 s$.

Food and Agriculture Organization of the United Nations (FAO). (2002). World Health Organization (WHO). Guidelines for the Evaluation of Probiotics in Food, Ontario, Canada.

Galla, N. R., Pamidighantam, P. R., Karakala, B., Gurusiddaiah, M. R. and Akula, S. (2017). Nutritional, textural and sensory quality of biscuits supplemented with spinach (Spinacia oleracea L.). International Journal of Gastronomy and Food Science 7, 20-26.

Genevois, C., Flores, S. and de Escalada, P. M. (2016). Byproduct from pumpkin (Cucurbita moschata Duchesne ex poiret) as a substrate and vegetable matrix to contain Lactobacillus casei. Journal of Functional Foods 23, 210-219.

Granato, D., Branco, G. F., Nazzaro, F., Cruz, A. G. and Faria, J. A. F. (2010). Functional foods and nondairy probiotic food development: Trends, concepts, and products. Comprehensive Reviews in Food Science and Food Safety 9, 292-302.

Guiné, R. P. F., Pinho, S. and Barroca, M. J. (2011). Study of the convective drying of pumpkin (Cucurbita maxima). Food and Bioproducts Processing 89, 422428.

Gurung, B., Ojha, P. and Subba, D. (2016). Effect of mixing pumpkin puree with wheat flour on physical, nutritional and sensory characteristics of biscuit. Nepal Journal of Science and Technology 9, 85-89.

Holt, S. H. A., Delargy, H. J., Lawton, C. L. and Blundell, J. E. (1999). The effects of highcarbohydrate vs high-fat breakfast on feelings of fullness and alertness, and subsequent food intake. International Journal of Food Sciences and Nutrition 50, 13-28.

Iravani, S., Korbekandi, H., Mirmohammadi, S. V. (2015). Technology and potential applications of probiotic encapsulation in fermented milk products. Journal of Food Science and Technology 52, 46794696.

Jeon, I. (1994). Analyzing Food for Nutrition Labeling and Hazardous Contaminants. Marcel Dekker Inc., New York, NY, USA.

Malmo, C., La Storia, A. and Mauriello, G. (2013). Microencapsulation of Lactobacillus reuteri DSM 17938 cells coated in alginate beads with chitosan by spray drying to use as a probiotic cell in a chocolate soufflé. Food and Bioprocess Technology 6, 795-805.

Norhayati, M. K., Mohd Fairulnizal, M. N., Zarron, A. Wan Syuriahti, W. Z., Rusidah, S., Aswir, A. R., 
Malays. J. Microbiol. Vol 15(5) 2019, pp. 366-372

DOI: http://dx.doi.org/10.21161/mjm.180238

Ang, J. L., Mohd Naeem, M. N., Suraiami, M., Mohd Azerulazree, J. and Vimala, B. (2015). Nutritional composition of selected commercial biscuits in Malaysia. Sains Malaysiana 44, 581-591.

Norshazila, S., Koy, C. N., Rashidi, O., Ho, L. H., Azrina, I., Nurul Zaizuliana, R. A. and Zarinah, Z. (2017). The effect of time, temperature and solid to solvent ratio on pumpkin carotenoids extracted using food grade solvents. Sains Malaysiana. 46, 231-237.

Passos, M. E. A., Moreira, C. F. F., Pacheco, M. T. B., Takase, I., Lopes, M. L. M. and Valente-Mesquita, V. L. (2013). Proximate and mineral composition of industrialized biscuits. Food Science and Technology 33, 323-331.

Rathore, S., Desai, P., Liew, C., Chan, L. and Heng, P. (2013). Microencapsulation of microbial cells. Journal of Food Engineering 116, 369-381.

Sarvari, F., Mortazian, A. M. and Fazeli, M. R. (2014). Biochemical characteristics and viability of probiotic and yogurt bacteris in yogurt during the fermentation and refrigerated storage. Applied Food Biotechnology 1, 55-61.

Savedboworn, W., Kerdwan, N., Sakorn, A., Charoen, R., Tipkanon, S. and Pattayakorn, K. (2017). Role of protective agents on the viability of probiotic Lactobacillus plantarum during freeze drying and subsequent storage. International Food Research Journal 24, 787-794.

Seyedain-Ardabili, M., Sharifan, A. and Tarzi, B. G. (2016). The production of synbiotic bread by microencapsulation. Food Technology and Biotechnology 54, 52-59.

Singh-Ackbarali, D. and Maharaj, R. (2014). Sensory evaluation as a tool in determining acceptability of innovative products developed by undergraduate students in food science and technology at the university of Trinidad and Tobago. Journal of Curriculum and Teaching 3, 10-27.

Tripathi, M. K. and Giri, S. K. (2014). 'Probiotic functional foods: Survival of probiotics during processing and storage'. Journal of Functional Foods 9, 225-241.

Yilmaz, N., Tuncel, N. B. and Kocabiyik, H. (2014). The effect of infrared stabilized rice bran substitution on nutritional, sensory and textural properties of cracker. European Food Research and Technology 239, 259265.

Yok, M. C. K., Gisong, S. A. D., Modon, B. A. and Rusim, R. (2015). Creating new market in integrated agriculture development area in Samarahan, Sarawak, Malaysia - Case study in the supply chain of Cucurbita sp. (pumpkin). Procedia - Social and Behavioral Sciences 224, 516-522.

Zhang, L., Chen, X. D., Boom, R. M. and Schutyser, M. A. I. (2018). Survival of encapsulated Lactobacillus plantarum during isothermal heating and bread baking. LWT - Food Science and Technology 93, 396404. 